\title{
A framework for a knowledge-based system for risk management in concurrent engineering
}

\section{Short title: \\ Knowledge based system for risk management in $\mathrm{CE}$}

\author{
Emmanuel Caillaud $^{1}$, Rose Crossland ${ }^{2}$, Didier Gourc ${ }^{1}$, Chris McMahon ${ }^{2}$, Luis Antonio Garcia ${ }^{1}$ \\ ${ }^{1}$ Centre Genie Industriel \\ ${ }^{2}$ Faculty of Engineering \\ Ecole des Mines d'Albi-Carmaux \\ University of Bristol \\ Campus Jarlard - Route de Teillet \\ 81013 Albi CT Cedex 09 - FRANCE \\ Phone : (+33) 5.63.49.31.56. \\ Fax : (+33) 5.63.49.31.83 \\ E-mail: \{caillaud, gourc\}@enstimac.fr \\ Queen's Building - University Walk \\ Bristol BS8 1TR - ENGLAND \\ Phone : (+44) 1179288100 \\ Fax : (+44) 1179294423 \\ E-mail: \{chris.mcmahon, \\ rose.crossland\}@bris.ac.uk
}

\begin{abstract}
Knowledge is a requirement for concurrent engineering, and therefore an approach to capture and organise the different knowledge to be taken into account in concurrent engineering is proposed. This approach, known as the "MEthodology for Knowledge Engineering for Concurrent Engineering" (MEKECE) is a dedicated application of knowledge engineering methodologies to concurrent engineering that involves a combination of case based reasoning and expert systems approaches aimed at managing risk. To manage concurrent engineering specific risks, the knowledge of the different tasks constituting product development must be captured and organised, and information on the causes of risks that have a threshold effect on time and on cost must be available in a convenient form for the participants in the process. The framework of this knowledge based system for risk management in concurrent engineering is presented.
\end{abstract}

Keywords: concurrent engineering, design, manufacturing, knowledge, knowledge based system, risk management. 


\section{INTRODUCTION AND OBJECTIVES}

Industrial firms must improve the quality of their products, reduce their cycle times and decrease their costs in order to meet their customers' requirements. This particularly applies for those companies that produce established products, and where new models are required at regular intervals. Such companies are involved in a constant search for improved approaches to design. In this regard, software-based approaches such as Computer-aided Engineering (CAE) and Product Data Management (PDM) do not always provide the expected support to process information, especially the knowledge which is necessary to manage design efficiently. Moreover, experienced designers produce better designs because of their ability to take into account the whole Product Design Development and Delivery $\left(\mathrm{PD}^{3}\right)$ process. This allows them to reduce the number of iterations between the steps of the process and therefore to reduce the time required for engineering activities and also the overall cost of the process. This is the basis of concurrent engineering ([1], [2]).

The efficiency and reliability of design processes can be improved if risk is taken into account (see McMahon [3]). Design risks are project risks (time and cost) and technical risks (with respect to design requirements): these aspects can be derived from the concepts of "design for X" (e.g. design for quality, design for performance or design for minimum cost) as considered in the design literature ([4], [5], [6], [7]). In view of its complexity and its compressed time scales, risk management is particularly important in concurrent engineering.

In order to allow all designers (including inexperienced ones) to define good solutions and to manage risk, the knowledge of the $\mathrm{PD}^{3}$ process must be available, formalized and structured in a way to ease its use by designers. In this paper, a framework for a knowledge based system for risk management in concurrent engineering to meet this requirement is proposed. Referring to the 7Ts (enabling agents of CE) presented in [1], we consider that such a tool can enable knowledge sharing amongst teams.

\section{CONCURRENT ENGINEERING, RISK MANGEMENT AND KNOWLEDGE ENGINEERING}

\subsection{Concurrent Engineering}

Concurrent engineering aims at decreasing the costs and time to market and at improving the quality of a product by carrying out in parallel activities which are usually done sequentially. In [1], Prasad describes $7 \mathrm{CE}$ principles that a company should aim for: parallel work-groups; parallel product decompositions; concurrent resource scheduling; concurrent processing; minimize interfaces; transparent communications; and quick processing. While the concepts of concurrent engineering (including Design for Manufacture and Assembly (DFMA), simultaneous product and manufacturing system design) are very simple in their definition, they are not always straightforward to implement. DFMA is a systematic procedure which simplifies the product structure, eases its assembly and minimizes the manufacturing costs. In this approach, the engineering process should allow strong decisions to be made at each step of the design process, taking into account the constraints of the following steps. Its principles and applications are presented by Huang [5].

In [8], a way of splitting design activities into elements is proposed on the basis of an algorithm that analyses the coupling between activities. Elements are then obtained which minimize the 
separation of coupled activities. A hierarchical approach to simultaneous design is presented in [9]. The various activities which must be done in parallel are considered at several levels of decomposition. The links between the activities can then be regarded more or less globally. The competition between several solutions for each element allows the best of them to be chosen. Integrating activities helps in taking into account the constraints of each actor in order to tend towards an optimal solution. Simultaneous design depends on the way links between activities are analyzed and modeled.

The basis of concurrent engineering is the management of knowledge from the design to the final stages of the product life-cycle. A number of approaches to this knowledge management have been proposed, including agent-based environments [10], knowledge-based engineering [11] and various other techniques drawn from artificial intelligence [12], but the topic is still the subject of active research.

\subsection{Risk management}

Risk management methodologies can allow project teams to identify and assess potential risk factors and take response actions in order to achieve the desired objectives of a given project. Several authors have summarized different risk management approaches :

- Cooper and Chapman's "risk engineering" approach [13] describes a family of risk assessment methodologies, which use the Controlled Interval quantitative modeling technique if quantification is needed. Their methodology is based on applying the basic Operational Research (OR) approach to a wide variety of project risk analysis problems. It is characterised by decomposition of the project into elements, and by the inclusion in the risk model of responses to uncertain events and of dependencies between uncertain events and between project elements. - More recently, Chapman and Ward presented a nine-phase generic risk management process structure [14], which is very similar to that provided by Chapman in the PRAM guide [15]. The define and focus phases involve identifying project objectives and scope, defining high-level activity base plans and scoping and planning the risk management methodology itself. During the identify phase, risks and responses are identified, as are secondary risks (arising from responses). The structure phase involves analysing the relationships between risks, responses and activities - it may involve building mathematical models. During the ownership phase, the extent to which risk will be shared with sub-contractors is determined, as well as individual owners being allocated to those risks which are the responsibility of the major company. Estimation involves estimating likelihood and impact of identified risks, numerically or qualitatively. This information is then evaluated to yield an indication of overall level of risk and of the most important contributors to the overall risk. The plan phase involves building a detailed activity base plan including expenditure and a risk management plan including contingency plans with trigger points. Once the project is implemented, the risk must be managed - progress is monitored, plans adjusted or re-formulated in the light of events, trigger events are responded to. Like the PRAM and Chapman and Ward approaches, the Riskman methodology [16], is intended to provide a framework for risk analysis and control, rather than a detailed prescription of techniques. The method provides a choice of three levels of analysis ranging from basic, where the probability and impact of a risk event occurring is assigned a qualitative value, for example "high"/"medium"/"low", through intermediate, where the probability of a risk event occurring is given as a percentage figure with a point value for the impact, to comprehensive which requires specification of the probability of a risk event as a PDF and its parameters. A software package supporting the methodology is now commercially available, which uses Monte Carlo simulation for a comprehensive level analysis. 
Risk management methodologies are generally composed of 4 steps: risk identification, risk assessment, risk treatment (mitigation) and risk monitoring [17]. As previously noted, two types of risks are considered: project management risks and technical risks (risks of non satisfaction of the requirements). Project management risk is generally considered to comprise schedule risk (the deadline is not respected) and cost risk (the $\mathrm{PD}^{3}$ overruns the projected cost). These risks are considered in the project management literature [18] [19]. After the risks listed in [20] and [21], we propose below a synthesis of the different typical risks encountered in design and moreover in concurrent engineering, on the basis of our experience of knowledge management in concurrent engineering. We consider that the main risks deal with the quality of the product (risks 1 and 2), the quality of the co-operation (risks 3 and 4), the availability of the resources and components (risks 5 and 6) and the adequacy of the product to its market (risks 7 and 8).

The risks can be of different categories: risks linked to the project (characteristics of the project, skills of the project team, ...), internal to the organisation (others departments, directors, ...) or external to the organisation (economic factors, market, ...).

\section{Risks within the project}

1. Requirements risk: the requirements do not satisfy the client needs.

2. Technical risk: the solution proposed does not fulfill the requirements.

3. Iteration risk: downstream steps imply iterations in the $\mathrm{PD}^{3}$.

4. Co-operation risk: the co-designers cannot mutually benefit from the relationship [22].

\section{Internal organization risks}

5. Resource risk: the resources required for design, manufacturing or delivery are not satisfactory or are not available when required.

6. Component risk: the materials or subcontracted parts required are not available as projected or their cost and quality do not fulfil the requirements.

\section{External organization risks}

7. Environmental risk: the product, its components or the manufacturing process adversely affect the environment (toxicity and/or prohibition).

8. Market risk: the market is not wide enough to make the product profitable.

These risks can directly affect the deadline, the global cost and quality of the $\mathrm{PD}^{3}$. We propose here to formalize and make available knowledge of the steps of the product development process in order to manage these risks.

\subsection{Knowledge Engineering}

Knowledge engineering aims to develop knowledge based systems efficiently. Knowledge engineering methodologies are based on artificial intelligence and cognitive science [23]. In order to establish the basic principles, let us consider two of the existing methodologies used in Europe for knowledge extraction which are MACAO and KADS.

MACAO [24] is a general method to support knowledge extraction. The aim of MACAO is to build a conceptually complete model of know-how from the capture of knowledge in various ways (interviews, analysis of data,...). MACAO is applied in four main steps:

- extraction and modeling of knowledge from data in the domain.

- modeling of the domain and the process followed by the expert. 
- definition of the complete conceptual model.

- implementation in a knowledge based system.

KADS [25] proposes a "top-down" process of knowledge extraction based on the transformation of pre-defined models. The aim of KADS is to propose a methodology for knowledge extraction starting from the modeling of the domain all the way to the implementation of the full system. KADS is made up of the following steps:

- study of the limits of the domain.

- extraction and modeling of the data.

- modeling of the domain.

- top-down modeling of the reasoning method based on generic models.

- extraction of the knowledge constituting the reasoning steps and realizing a prototype of the model.

KADS can be supported by software such as KADS Tool (ILOG) and Open KADS (Bull).

These two methodologies make a link between the psychological approach to human knowledge and the extraction of the necessary information in order to develop a knowledge based system.

\subsection{Knowledge-Based Systems}

The results of the knowledge methodology are generally implemented in knowledge based systems [26] such as expert systems or case-based reasoning systems.

Expert system applications are often based on expert system shells - development tools that allow modeling and implementation of knowledge expressed by rules (see Figure 1). An expert system shell allows knowledge to be embedded and modified in a knowledge based system. Of course, knowledge must be inferred (by the inference engine element of the system) and must follow the identified reasoning. In many expert system shells, knowledge is expressed as a set of production rules: "IF ... THEN ...".

The main advantage of expert system shells is the ease of modification of the rules but the consequence is the difficulty of their validation. This type of tool leads to a strict formalization of knowledge and offers a form of expression and use which is understandable by the experts.

An expert system for risk management in engineering was developed by Niwa [27]. His "humancomputer co-operative system" used a model of risk causes based on historical data from previous projects to help in risk identification for large scale construction projects. A set of production rules were developed of the form:

if $<$ risk factors $>$ then $<$ risk factors $>$

if $<$ risk factors $>$ and $<$ work packages $>$ then $<$ risks $>$

if $<$ risks $>$ and $<$ work packages $>$ then $<$ risks $>$

Here, a "work package" is defined in a two-dimensional space which has a set of standard activities along one axis (e.g. procurement, installation, etc.) and standard objects (equipment or buildings, parts of the product model) along the other, and is used to determine which knowledge about risks and risk factors is relevant to the activity currently subject to risk assessment. The system used both forward and backward reasoning methods, along with an informal "knowledge association" method for building dynamic associations between a starting risk and other risks, based on keyword search.

A second technique, Case Based Reasoning, associates a solution $\mathrm{S}$ to the data of a new problem $\mathrm{P}$ [28]. The solution $\mathrm{S}$ is derived from the solution $\mathrm{S}^{\prime}$ of the problem $\mathrm{P}^{\prime}$ which is regarded as similar to the problem $\mathrm{P}$. This is realized in three steps: the search for a similar problem $\mathrm{P}^{\prime}$, the 
modification of the solution $\mathrm{S}^{\prime}$ to the desired solution $\mathrm{S}$ and the storage of the problem $\mathrm{P}$ and the solution $\mathrm{S}$ for their future reuse (see Figure 2).

The expert system approach implies the formalization of the deep knowledge associated with the problem. By deep knowledge we mean the knowledge which makes the difference between an expert and a novice. This structuring of knowledge can be rationalized but implies a difficulty of validation (the new system does not have exactly the same approach as the expert). The approach by analogy (case-based reasoning) is closer to the expert's habits but it hides the knowledge used because the solution is not generated but deduced. In this paper, we propose to mix these approaches to capitalize on the different engineering knowledge which must be taken into account in concurrent engineering.

\subsection{Knowledge sharing in concurrent engineering}

"In CE, cooperation is required between CE teams, management and suppliers. A knowledge based support system will help the participating teams in decision making and to reflect balanced views" (pp. xxv in [2]).

After [29], information sharing requires the information should be:

- reliable

- accessible

- compatible

- respectful of legal aspects

While information sharing is the basis of CE, we consider that only a part of the knowledge used in $\mathrm{CE}$ has to be shared. Each specialist will bring to the process particular domain-specific knowledge, most of which will necessarily only be used by the specialist. The correct application of this knowledge depends, however, on the timely availability of reliable information to the specialist.

Notwithstanding the above remarks, there is considerable scope in CE for the provision of tools to support both knowledge and information sharing. In [30], Schaffer, Eck and Roller propose an architecture for a shared knowledge base supporting CE for interdisciplinary (mechanical and electrical engineering) and geographically distributed teams. They propose an application mixing a cooperative transaction model, rules and parametric constraints. The authors underline the difficulty to capture and to handle the interdisciplinary dependencies.

Matta, Corby and Prasad present in [31] a generic library of knowledge components to manage conflicts in CE tasks. They distinguish private knowledge from shared knowledge (accessible to other users).

Knowledge sharing allow the generation of new knowledge thanks to synergy. In [22], Yoshimura and Yoshikawa propose a methodology for evaluating the effectiveness of knowledge sharing. They consider that the design is cooperative only if each designer benefit from the others. They propose to identify the acquired knowledge for each item of the product design and to evaluate numerically the benefit for each designer based on the Analytic Hierarchy Process method. If the designers both benefit from the knowledge sharing, they consider the cooperative work as viable.

In order to make $\mathrm{PD}^{3}$ more efficient, it is important to identify and to understand what is critical. We consider that the part of the knowledge implying critical decisions must be shared. On this basis, a risk management approach can be used. These ideas are developed in the next section. 


\section{KNOWLEDGE ENGINEERING FOR RISK MANAGEMENT IN CONCURRENT ENGINEERING}

In [32], Prasad classifies different concurrent engineering techniques according to the degree of creativity, the degree of co-operation and the degree of uncertainty. He considers that knowledge-based tools can be used for high levels of uncertainty, creative and co-operative tasks. The problem is then to develop these knowledge-based systems.

On the basis of knowledge engineering methodologies and taking into account the implementation approaches of expert systems and case-based reasoning, and on the basis of previous work ([33], [34]) the MEKECE methodology for risk management in concurrent engineering has been proposed. MEKECE stands for "MEthodology for Knowledge Engineering for Concurrent Engineering", and is composed of a knowledge engineering methodology dedicated to engineering and some principles which must be followed to promote concurrent engineering.

\subsection{Knowledge engineering for $\mathrm{PD}^{3}$}

MEKECE is designed to be applied to each step of the $\mathrm{PD}^{3}$ engineering process. We propose a progressive process for technological knowledge acquisition, modeling and validation. Knowledge comes from two sources: previous cases and engineering methodology, and this division has therefore led to the mixed case based reasoning and expert systems approach in MEKECE, in which cases are clustered on the basis of their reasoning processes.

MEKECE is composed of the following steps: an acquisition of knowledge by immersion in the enterprise, a modeling of the area of study, a clustering of cases, a procedural structuring of the process followed, a structured expression of rules and data and a validation by an exploitation of knowledge using an expert system. It is based on the increasing refinement of the knowledge analysis and on cycles of modeling then validation with the concerned actors.

To acquire and model knowledge, the domain must first be analyzed. Different types of knowledge can be distinguished (see Figure 3).

On the basis of the cases, we must consider the knowledge which is specific to a single case. At an upper abstraction level, we consider the generic knowledge which is common to a set of cases. General principles can be applied to any case but are far too general to help a beginner. If general principles are often available in the literature, generic and specific knowledge must be formalized: this is the real expert's know-how.

We propose a procedural expression for the steps of the reasoning: for each step of the $\mathrm{PD}^{3}$ process, the objective, the necessary data, the constraints and the outputs must be defined. The constitutive rules of each step are then listed as production rules or as procedures. The nature of the objectives do not correspond to a binary answer (objective reached or not) but to the expression of levels of satisfaction in their fulfilment. The set of data needed often consists of: basic and elaborate data resulting from a transformation (aggregation, composition, refinement,...) of the basic data. The constraints limit the space of the admissible solutions. Notice that these constraints will be used in a concurrent engineering approach in order to take into account the steps of the engineering process which follow. The outputs result from the commitment to the expert's rules.

We propose a validation of the knowledge through its exploitation by a knowledge based system. The approach is detailed through an example of tooling design in [35]. Such an application has been chosen for the criticality of tools in the global cycle of the product. Regarding tooling design, each tooling element must be analyzed and its specific knowledge expressed. The parts 
leading to a similar design approach are clustered in a family. Then, the common rules used for this set are expressed (generic knowledge). It should be emphasised that deriving the design rules from the cases requires much effort. At the upper level, the classical rules for tool design are expressed. These general principles are generally known and expressed in the literature. A knowledge-based system can then be implemented. We propose to use a CBR system such as KATE and to implement the rules of design with an expert system shell. The general principles and the main terms used can be expressed in a help system (with HTML files, for example).

Risks can be managed on the basis of this knowledge. For instance, let us consider the risk of iteration between the tooling design and the routing definition. In this case, the main decisions of the tooling design (having an impact on the routing re-definition) must be identified and expressed as constraints to the routing definition. For example the choice of a tool path can drastically modify fixture design.

\subsection{Knowledge engineering for risk management in concurrent engineering}

This approach consists of 4 steps:

1. Knowledge engineering for the whole $\mathrm{PD}^{3}$ process.

2. Knowledge engineering for risk identification for each task.

3. Knowledge engineering for risk evaluation.

4. Knowledge engineering for risk management in concurrent engineering.

\subsubsection{Knowledge engineering for the whole $P D^{3}$ process}

We propose to apply MEKECE to the knowledge management of product development projects to record the risks which occur and their effects, in order to be able to use this knowledge for a

new $\mathrm{PD}^{3}$ process. The clustering of the cases is then based on similarity of the risks. This will allow management of projects according to their risk characteristics. This requires a formalization of the $\mathrm{PD}^{3}$ process as a series of tasks with knowledge associated with each task. The MEKECE approach must be carried out coherently for the whole $\mathrm{PD}^{3}$ process: the product design, process planning (including tooling design), manufacturing and delivery.

\subsubsection{Knowledge engineering for risk identification for each task}

Following the clustering of cases, knowledge must be formalized and validated for each $\mathrm{PD}^{3}$ task in order to identify, evaluate and manage risk. On the basis of the list of risks presented in section 2.2., the risks of the product development process under consideration must be listed. For each risk, the possible causes must be identified and their occurrence must be defined. The possible actions that result if the risk occurs must be defined and linked to the tasks of $\mathrm{PD}^{3}$.

\subsubsection{Knowledge engineering for risk evaluation}

A simulation can allow evaluation of the effect of risks and uncertainty on the tasks and on the quality, cost and time of the $\mathrm{PD}^{3}$. This can be achieved using classical Monte Carlo simulation. This is the approach taken in the RiTo risk management tool reported by McMahon [3] based on [36]. The effect of the treatment of some risks can then be quantified. 


\subsubsection{Knowledge engineering for risk management in concurrent engineering}

To limit redesign, risk management knowledge must be captured and the key characteristics that have a threshold effect on both time and cost must be available for the product design. This implies a significant effort being expended on knowledge engineering in the previous projects:

- The identification of the events that will have a major effect on the steps which follow can be realized if the knowledge for each step has been captured.

- The events implying a risk of important impact on time, quality and cost must be considered for each step.

- The causes of these risks must be analyzed in order to determine those coming from the previous steps.

- In order to manage the risks in a concurrent engineering environment, the causes of major decisions must be expressed in such a way that they can be understood and used as constraints for the other steps. This implies that the previous steps have been formalized in order to apply the constraints at the right step of the reasoning. This also allows easy expression of the constraints, which may be used to limit the space of solutions at a precise step of reasoning.

To promote concurrent engineering, major decisions must be identified and expressed as understandable constraints which can be used during the first steps of the design-manufacturing process.

\section{A FRAMEWORK OF A KNOWLEDGE-BASED SYSTEM FOR RISK MANAGEMENT IN CONCURRENT ENGINEERING}

We present here a framework of a knowledge-based system linking an expert system, case based reasoning and risk management, and we describe its possible use.

\subsection{Knowledge-Based System}

The knowledge-based system must use the different available knowledge in order to manage the design risks. In Figure 4, we present the general framework of the system. For a new product development, the project structure that can be derived from similar cases (projects) is selected. These similar projects are then considered as references and as examples for the use of rules for risk management. The help module can also be illustrated by these examples.

On this basis, different software must be linked- for example comprising project management, case-based reasoning, expert-system, risk management and help functions. As examples, RISKMAN [37] [17], Microsoft Project, Nexpert Object, Kate and Netscape can be considered as software for risk management, project management, expert system shell, case based reasoning system and hypertext help respectively.

\subsection{Application}

The use of the proposed knowledge based system comprises various steps. These steps have been defined after analyzing the specific kinds of project to be developed. For this first approach, it should be specified what kind of project will be developed and for which sector it will be developed. This is an important point to analyze, because, depending on this, the kind of data base and the kind of expert system to be used must be defined. 
The first approach to the methodology is made by a flow diagram (figure 5) that shows the structure proposed.

Each of these steps is explained in the next sections.

\subsubsection{New project definition}

First of all, the main features of the project must be described :

- Customer/market: the person or enterprise the product is designed or manufactured for is defined or the sector or the specific sector we want to "attack" is identified.

- Reuse: the customer has already used or bought our products, and we have the information on the requirements and the kind of "extra value" expected.

- Defined requirements: the customer has already given us a list with all the expected requirements (materials, tolerances, etc.).

- Cost defined: the customer has already given us a maximum price specification; this means that in order to make our product profitable our cost should be under that price, this cost politics must be defined by company management, and the expected profit margin also.

- Kind of product: the product family must be described.

- Time: the delivery time and the production time are two factors that must be considered, because depending on these the project may imply more or less resources and a higher or lower budget. Time is also a factor that may increase or decrease the level of difficulty in the project.

- Budget: available economic resources that were assigned to the project. The budget is also considered a major factor to determine the project limits.

- Risks: specific risks can be considered as particularly problematic for the project ( $a$ priori).

As a result of the previous step, we obtain the characteristics of the new project: we are able to make a first design and we are also able to determine what should we do. The market research is done and we have already determined the main features of the product to satisfy the market requirements.

\subsubsection{Objective Definition}

One of the most important points to be analyzed is the objective of the project. This means that the main purpose of the project must be defined, by analyzing the expected results.

All the proposed objectives must be coherent and must be analyzed to give tangible results. This means that all the obtained results from experiments or projects must be measurable (money, time, resources used, etc.). We should define the design and architecture of the product, how will it be done and the expected impact on the company development. A goal for the product must be defined and the required resources to develop it must be evaluated.

The marketing department and the development and manufacturing department should work together in order to analyze the project feasibility from the point of view of availability of resources to develop the product. This part of the project includes the preliminary design and prototypes.

This step concerns the internal organization requirements such as the analysis of the producibility of the product with the available resources. At this point we also analyze the 
expected impacts inside the company. A cost benefit analysis should be undertaken to determine if the costs and resources are satisfactory to develop the defined product.

\subsubsection{Similarity research}

The new $\mathrm{PD}^{3}$ project must be formalized and expressed as a project. On the basis of the new project definition, we recommend the use of CBR (Case Based Reasoning) to identify previous projects having the same key features and then to use them as a reference for the structure of the new project, which can be expressed, for example, in Microsoft Project. The most similar previous project must be adapted to the new project definition. The project management and risk management rules can be represented in an Expert System (ES) to support the adaptation of the case.

This step is basically the definition of parameters in order to determine what kind of "similarity" we are expecting. The similarity researched can be one of the following types: task time, cost, kind of project, etc. An Index should be developed, in order to allow us to define the "similarity" we are expecting. The Index should be evaluated using all the characteristics of the old projects, such as department responsible, resources consumed, time expended, tasks undertaken, etc.

\subsubsection{New Project Structure}

The project plan must be developed following the similarity research. At this step, we use MS Project to help us to define all the tasks, times, resources, etc., required for the project based on the similarity research.

During this step, the Project will be defined and formalized as a Gantt Chart or a Pert diagram. The risks obtained from the CBR will be derived from the cases and will be added to the critical path or to a list of all the possible failures during the project.

During the CBR work, the following items are studied:

- Tasks: the expert system will help us to define which of them are relevant or not to the problem by using the MEKECE methodology. The tasks must also be analyzed based on the production quantity, expected quality, lead time, etc.

- Risk: the identified risks can be obtained and handled by a risk management methodology such as Riskman. All the recently acquired risks will be required to formalize the risk methodology. The expected risk budget should also be proposed by the KBS.

- Time: the expected time for each task and the expected overrun time for the project and all the tasks must be analyzed. The critical path should also be constructed in order to obtain an optimized time.

- Resources: some resources used in previous projects and also the actually available resources for the present project must be analyzed in terms of their capacity, quantity, performance, etc. This will help to associate risks with the resources.

- Budget: an expected budget will be presented in this step, in order to obtain the expected ROI (Return On Investment) time and the required investment, this will help the risk management and also will help to analyze the financial decision-making for the project.

After the CBR has helped us to define these issues we can proceed to use the MS Project software to formalize the project, time, etc.

In this step we should obtain:

- A PERT chart 
- A Gantt Chart

- A cost analysis

- A description of required resources, among other information.

\subsubsection{Risk Management}

Risk management methodologies were presented in part 2.4.

In this step it is important to note that projects are described using Microsoft Project and that a $\mathrm{MS} /$ Windows $^{\mathrm{TM}}$ interface can be used thus allowing exchange of data between the different applications.

\subsubsection{Risk Identification and analysis}

At this stage the different tasks of the new $\mathrm{PD}^{3}$ must be analyzed and different types of risks must be listed. Each risk must be linked to a set of tasks. For each risk a set of possible actions to be taken if the risk occurs must be defined. On the basis of similar projects, risks and their actions can be derived. For example, actions in case of environmental risk may be to select a new material or a new process.

The causes which can give rise to a risk must be listed and linked to the risks. For example, the cause "process prohibited" is linked to environmental risk. Moreover these causes must be quantified. Similar projects must be used as references for the quantification.

At this stage, risk can be simulated. The results obtained can be compared to those from previous projects to verify the accuracy of the simulations. Simulation allows identification of the risks which could particularly affect the $\mathrm{PD}^{3}$ process. Then their associated causes must be analyzed in order to limit their occurrence by using them as constraints on the previous tasks.

\subsubsection{Validation}

By this point, the project management approach utilizing the KBS methodology in a $\mathrm{CE}$ environment should be close to complete. This means that the Gantt chart, the PERT diagram, the risk chart and all the risk analysis should be formalized by this stage and all the expected times, overruns, etc., must be already estimated.

In this step, all the "rules" of the proposed project should be validated. This means that the expert system should allow us to define which tasks are possible and which ones are not allowed. It should do this by comparing the structure obtained for the project after doing all the previous steps with the older projects and by either corroborating or rejecting the obtained result.

\subsubsection{Final Structure of the project}

After the validation is done, we obtain the actual project structure which will allow us to determine the real critical path, critical resources, etc. By this point we should be able to begin the project with precedent knowledge applied to this project and at the same time with risks on the new project reduced.

\section{CONCLUSION}

Concurrent engineering is founded on the possibility of using the knowledge of later stages of the design-manufacturing process as constraints for the product design process. We propose here a framework for a knowledge-based system for risk management in concurrent engineering. The 
KBS requires a description of the risk knowledge from previous product development projects. This implies the use of a dedicated knowledge engineering methodology.

The quality of the results directly depends on the similarity of the new project with the previous ones. This implies that the knowledge based system must be dedicated to a firm or a family of projects.

The use of such an approach for other domains (bio-industry, pharmaceutics, services, etc.) is under study.

\section{REFERENCES}

[1] Prasad, B. 1996. "Concurrent Engineering Fundamentals: Vol. 1, Integrated Product and Process Organisation", One Saddle River, New Jersey: Prentice Hall PTR.

[2] Prasad, B. 1997. "Concurrent Engineering Fundamentals: Vol. 2, Integrated Product and Process Organisation”, One Saddle River, New Jersey: Prentice Hall PTR.

[3] McMahon, C. A. 1998. "Engineering design: management of information and uncertainty", proceedings of IDMME'98 Compiègne (France), 27-29 May, Primeca/CIRP, pp. 3-18.

[4] Pahl, G. and W. Beitz. 1996. "Engineering Design: a Systematic Approach", trans. K. Wallace, L. Blessing and F. Bauert, 2nd Edition, Springer-Verlag.

[5] Huang, G. Q. 1996. "Design for X", Chapman \& Hall.

[6] Suh, N.P., "The principles of design”, MIT, Oxford University Press, 1990.

[7] Grabowski H., Lossack R.-S., El Mejbri E.-F., "Towards a universal design theory", International CIRP Design Seminar, Enschede (NL), 25-26 March, pp. 47-56, Kluwer, 1999.

[8] Kusiak, A. and J. Wang. 1993. "Efficient organizing of design activities"; International Journal of Production Research, Vol. 31, n4, pp. 753-769.

[9] O'Grady, P.J., Y. Kim and Young, R.E. 1994. "A hierachical approach to concurrent engineering systems"; International Journal of Computer Integrated Manufacturing, Vol. 7, n³, pp. 152-162.

[10] Sobolewski, M. 1996. "Multi-agent knowledge-based environment for concurrent engineering applications", Concurrent Engineering: Research and Applications, Vol. 4, $\mathrm{n}^{\circ} 1$, pp. 89-97.

[11] Su, C-J., M. Tseng and R.J. Mayer. 1997. "EKAMD-a knowledge-based concurrent engineering support system", Concurrent Engineering: Research and Applications, Vol. 5, $\mathrm{n}^{\circ} 1$, pp. 59-76.

[12] Cormier, D., P.J. O'Grady and E. Sanii, E. 1998. "A constraint-based genetic algorithm for concurrent engineering"; International Journal of Production Research, Vol. 36, nº, pp. 1679-1696.

[13] Cooper, D. F. and Chapman, C, 1987, "Risk Analysis for Large Projects: Models;, Methods and Cases", Chichester : John Wiley \& Sons Ltd.

[14] Chapman, C. B. and Ward, S., 1997, "Project Risk Management: Processes, Techniques and Insights", Chichester : John Wiley \& Sons Ltd.

[15] Simon P., Hillson D., Newland K. (eds), 1997, "Project Risk Analysis and Management Guide (PRAM)". Association for Project Management.

[16] Carter, B., Hancock, T., Morin, J-M., and Robins, M., 1994. "Introducing RISKMAN Methodology: The European Project Risk Management Methodology", NCC Blackwell Ltd., Oxford, UK 
[17] Conroy G., H. Soltan. 1998. "Conserv, a project specific risk management concept", International Journal of Project Mangement, Vol. 16, nº 6 , pp. 353-366.

[18] Giard V., 1991, "Gestion de projets", Economica

[19] Williams, T., 1995, "A classified bibliography of recent research relating to project risk management", European Journal of Operational Research, vol. 85, pp. 18-38.

[20] Larson, N. and A. Kusiak, 1996. "Managing design processes: a risk assessment approach”, IEEE Transactions on SMC, part. A, Vol. 26, n6, pp.749-759.

[21] Sarbacker, S. D. and K. Ishii, 1998. "Application of a framework for evaluating risk in innovative product development”, International Journal of Agile Manufacturing, Vol. 1, n², pp. 123-141.

[22] Yoshimura, M. and K. Yoshikawa. 1998. "Synergy effects of sharing knowledge during cooperative product design", Concurrent Engineering: Research and Applications, Vol. 6, $\mathrm{n}^{\circ} 1$, pp. 7-14.

[23] Aussenac, N., P. Laublet and C. Reynaud. 1996. "Acquisition et ingénierie des connaissances, tendances actuelles". Cepadues, Toulouse.

[24] Aussenac, N. 1989. "Conception d'une méthodologie et d'un outil d'acquisition de connaissances expertes", PhD Thesis, Université Paul Sabatier, Toulouse.

[25] Tansley, D.S.W. and Hayball, C. C., 1993. "Knowledge-based Systems Analysis and Design: a KADS Developer's Handbook", Prentice Hall.

[26] Barr, A. and E.A Feigenbaum. 1981. "The Handbook of Artificial Intelligence", W. Kaufmann Inc., Los Altos, California.

[27] Niwa, K. 1989. "Knowledge-Based Risk Management in Engineering”, John Wiley and Sons, Inc., New York, USA.

[28] Kolodner, J.L. 1993. “Case Based Reasoning”, Morgan San Mateo, CA.

[29] Thoben, K-D., Weber, F. 1999. "Designing information and communication structures for concurrent engineering", ICED'99, Munich (G.), August 24-26, Technische Universitat Munchen, pp. 989-994.

[30] Schaffer, D., Eck, O., Roller, D. 1999. "A shared knowledge-base for interdisciplinary parametric product data models in CAD", ICED'99, Munich (G.), August 24-26, Technische Universitat Munchen, pp. 1593-1598.

[31] Matta, N., Corby, O., Prasad, B. 1998. "A generic library of knowledge components to manage conflicts in CE tasks", Concurrent Engineering: Research and Applications, Vol. 6, n' 4 , pp. 274-287.

[32] Prasad, B. 1998. "How tools and techniques in concurrent engineering contribute towards easing cooperation, creativity and uncertainty", Concurrent Engineering: Research and Applications, Vol. 6, ${ }^{\circ} 1$, pp. 2-5.

[33] Caillaud, E. and D. Noyes. 1996. "Knowledge engineering for design", ESDA'96, ASME, Montpellier (France), Vol. 8, pp. 1-8

[34] Noyes, D. and E. Caillaud. 1998. "CAD/CAM integration: an efficient approach in a fixture design framework”, in: Rapid Response Manufacturing, pp. 191-211, Chapman \& Hall.

[35] Caillaud E. 1999. "Knowledge engineering for concurrent engineering", CIRP-Design, Enschede (NL), 25-26 March, Kluwer, pp. 229-238.

[36] Crossland R., 1997, "Risk in the Development of Design", PhD Thesis, University of Bristol.

[37] http://www.ccc.fi/riskman/ 


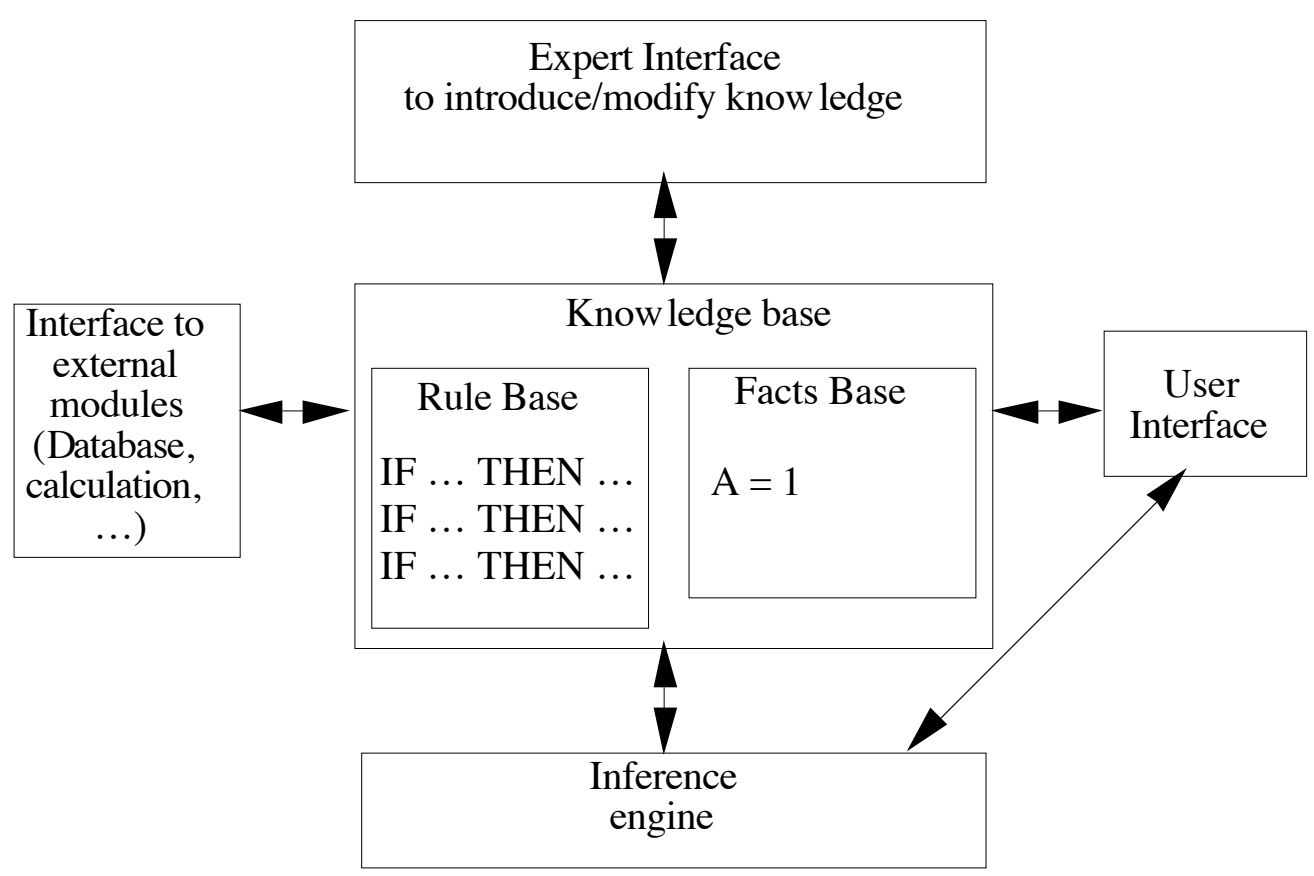

Figure 1. Architecture of an expert system shell. 


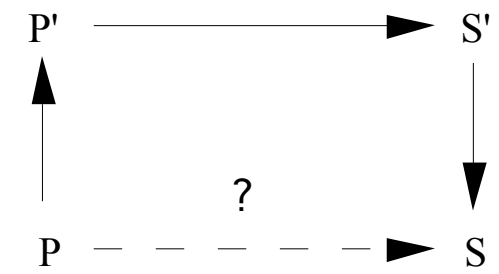

Figure 2. The principle of Case Based Reasoning. 


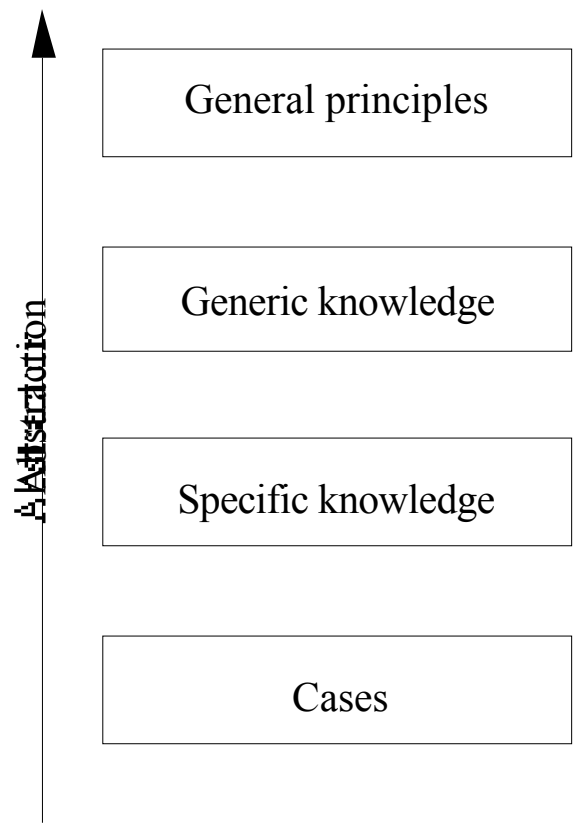

Figure 3. Different types of knowledge. 


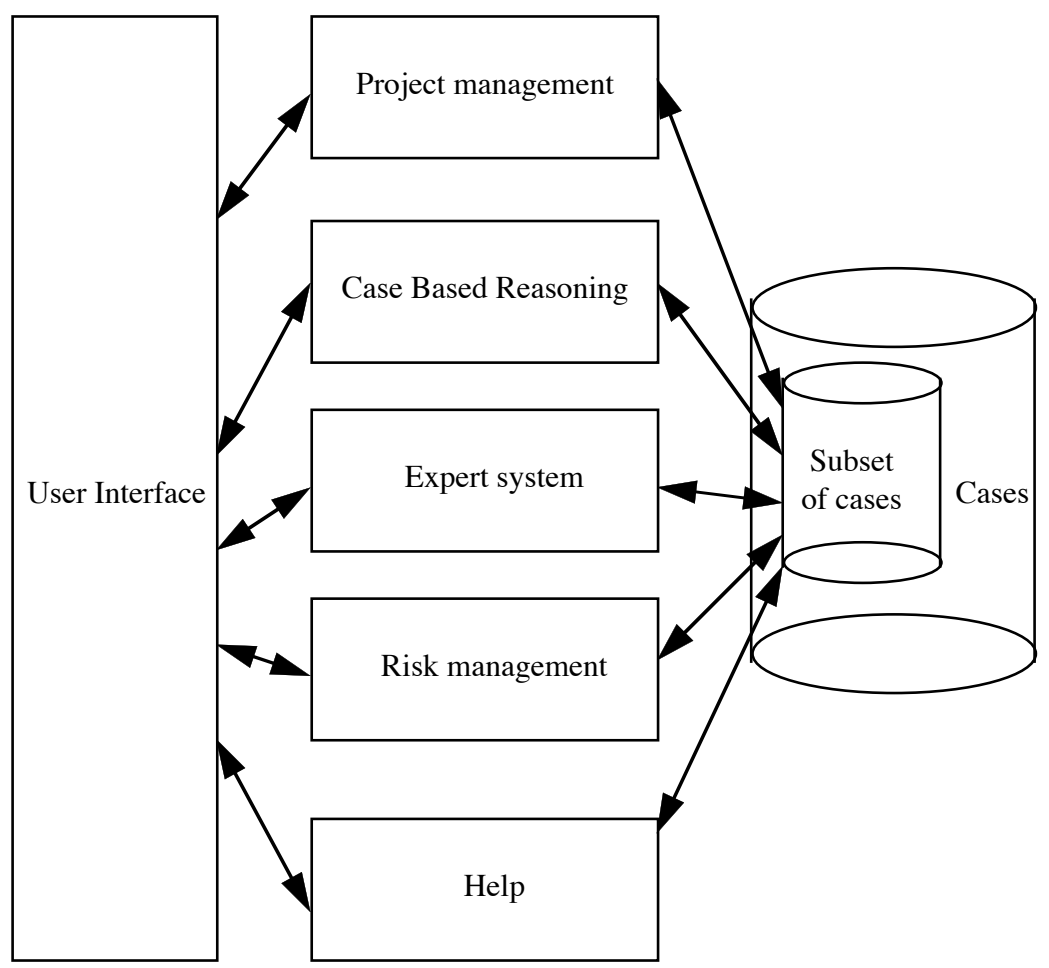

Figure 4: General framework of the Knowledge Based System. 


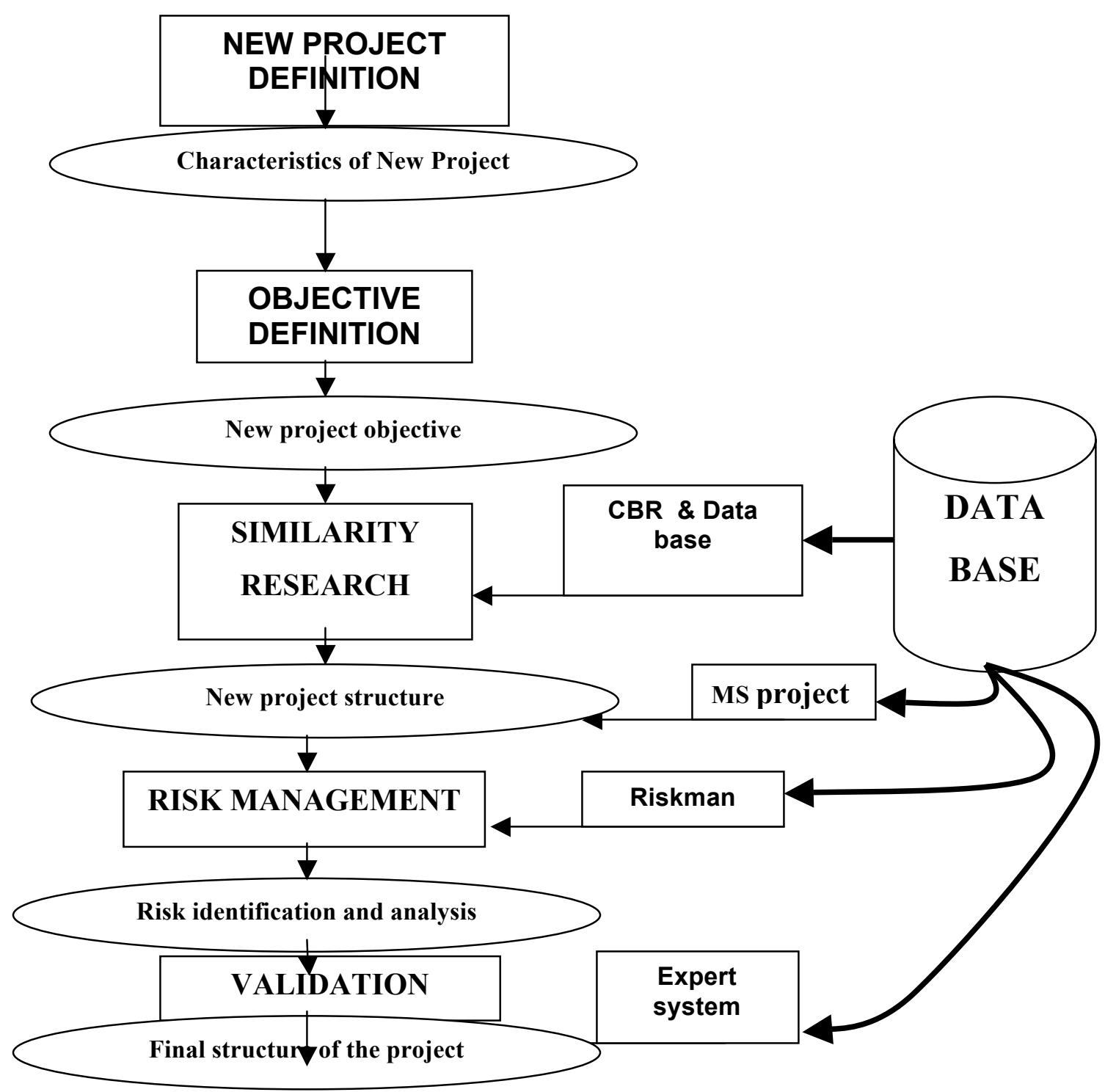

Figure 5: Flow diagram of the KBS 